\title{
Conflict, trust, and effectiveness in teams performing complex tasks : a study of temporal patterns
}

Citation for published version (APA):

Raes, A., Heijltjes, M. G., Glunk, U., \& Roe, R. A. (2006). Conflict, trust, and effectiveness in teams performing complex tasks : a study of temporal patterns. METEOR, Maastricht University School of Business and Economics. METEOR Research Memorandum No. 008 https://doi.org/10.26481/umamet.2006008

Document status and date:

Published: 01/01/2006

DOI:

10.26481/umamet.2006008

Document Version:

Publisher's PDF, also known as Version of record

\section{Please check the document version of this publication:}

- A submitted manuscript is the version of the article upon submission and before peer-review. There can be important differences between the submitted version and the official published version of record. People interested in the research are advised to contact the author for the final version of the publication, or visit the DOI to the publisher's website.

- The final author version and the galley proof are versions of the publication after peer review.

- The final published version features the final layout of the paper including the volume, issue and page numbers.

Link to publication

\footnotetext{
General rights rights.

- You may freely distribute the URL identifying the publication in the public portal. please follow below link for the End User Agreement:

www.umlib.nl/taverne-license

Take down policy

If you believe that this document breaches copyright please contact us at:

repository@maastrichtuniversity.nl

providing details and we will investigate your claim.
}

Copyright and moral rights for the publications made accessible in the public portal are retained by the authors and/or other copyright owners and it is a condition of accessing publications that users recognise and abide by the legal requirements associated with these

- Users may download and print one copy of any publication from the public portal for the purpose of private study or research.

- You may not further distribute the material or use it for any profit-making activity or commercial gain

If the publication is distributed under the terms of Article $25 \mathrm{fa}$ of the Dutch Copyright Act, indicated by the "Taverne" license above, 
Conflict, Trust, and Effectiveness in Teams Performing Complex Tasks:

A Study of Temporal Patterns

\author{
Anneloes M.L. Raes \\ Mariëlle G. Heijltjes \\ Ursula Glunk \\ Robert A. Roe \\ Universiteit Maastricht \\ Faculty of Economics and Business Administration \\ Department of Organization and Strategy \\ P.O. Box 616 \\ 6200 MD Maastricht \\ The Netherlands \\ Tel: +31.43 .3883812$ \\ Fax: +31.43 .3884893$ \\ A.Raes@os.unimaas.nl \\ M.Heijltjes@os.unimaas.nl \\ U.Glunk@os.unimaas.nl \\ R.Roe@os.unimaas.nl
}

Acknowledgement: The authors would like to thank Mary Waller for reviewing an earlier version of this paper. We also gratefully acknowledge the help of Anouk Broen, Victor van der Linden, Susanne Simons and Liselotte Wentrup for their assistance in data collection. 


\title{
Conflict, Trust, and Effectiveness in Teams Performing Complex Tasks: A Study of Temporal Patterns
}

\begin{abstract}
In this study we analyze the evolution of intra-team conflict and trust in teams that perform complex tasks. Using a longitudinal research design with six time intervals over a period of ten months, we collected data on 41 teams. Our findings suggest the existence of two distinct temporal patterns. One pattern develops in a stable manner and is characterized by high levels of trust and relatively low levels of task and relationship conflict. The other pattern is unstable with low, deteriorating levels of trust and high, amplifying levels of task and relationship conflict. These patterns are associated with significant differences in team effectiveness. On a self-perception as well as a stakeholder measure of team effectiveness, teams with stable patterns outperformed teams with unstable patterns.
\end{abstract}

Keywords: conflict; trust; temporal patterns; time; team effectiveness 


\section{INTRODUCTION}

Conflict and trust are both considered important aspects of team functioning. Studies on the role of conflict in teams have typically focused on how various types of conflict in team interaction influence effectiveness (Amason, 1996; Jehn, 1995; Jehn \& Bendersky, 2003). This research has shown that the perception of interpersonal incompatibilities among team members - i.e. relationship conflict -, negatively influences team effectiveness (Jehn, 1995; Jehn \& Shah, 1997). Moderate levels of perceived differences relating to the task at hand i.e. task conflict -, have been found to influence team effectiveness positively (Jehn, 1995).

Intra-group trust has been acknowledged as facilitating cooperation among people (Mayer, Davis \& Schoorman, 1995; McAllister, 1995) and forms an important element of the interpersonal and groups dynamics in teams (Costa, Roe, \& Taillieu, 2001). Trust exists when the partners in an exchange believe that they will not be taken advantage of by others who are involved in the same exchange (Zucker, 1987; Bateson, 1988). As such, trust leads to expectations among team members about how the other team members will behave (Jones \& George, 1998).

Despite the fact that conflict and trust are important aspects of the interaction processes in teams, little is known about how intra-group conflict and trust interact over time and how patterns of interaction influence team effectiveness. As a growing number of small group researchers have acknowledged, time is an inherent aspect of team functioning and should, therefore, be incorporated into research on teams (Arrow, McGrath, \& Berdahl, 2000; Ilgen, Hollenbeck, Johnson, \& Jundt, 2005). As McGrath, Arrow, \& Berdahl (2000) put it: "To reground the study of groups in the reality of group life as it occurs in the world, we must acknowledge and study groups as embedded [....] within the passage of time" (p. 95).

This call seems especially relevant for conflict and trust, since these concepts have been proposed to vary over time. For example, for conflict it has been suggested that not only 
the absolute value, but also the moment in which a certain type of conflict occurs determines the impact of conflict on performance (Jehn \& Mannix, 2001). Also for trust, an evolution over time has been proposed (Jones \& George, 1998; Williams, 2001). Conflict and trust may also interact. For instance, conflict may reduce the level of trust at later times, or inversely, a high level of trust may prevent the emergence or escalation of conflict. However, this possibility has to our knowledge never been investigated.

Therefore, the aim of the present study is to examine the joint development of conflict and trust in teams within a longitudinal framework. More specifically, we will focus on temporal patterns of conflict and trust, and their relationship with team effectiveness. We add to the literature on team processes and effectiveness by proposing a new method for identifying temporal patterns and by showing how such patterns relate to team effectiveness. In the following, we will first elaborate on conflict and trust in a time perspective. Next, we will present hypotheses on how patterns of conflict and trust evolve over time and how they relate to management team effectiveness.

\section{BACKGROUND, THEORY AND HYPOTHESES}

\section{Dynamics of Conflict}

Team researchers have paid attention to several temporal aspects of team functioning: team development (Tuckman, 1965; McGrath et al. 2004), the development of mental models (Gevers, 2004), the evolution of group performance (Poole \& Roth, 1989; Gersick, 1988, 1989), and the timing of adaptive behavior (Waller, 1999), are some examples. However, research on group conflict has predominantly taken a static approach. One exception are Jehn and Mannix (2001), who investigated whether high performing task groups scored differently on three types of conflict than low-performing task groups and indeed found support for their hypotheses. High performing groups followed a pattern in which Gersick's (1988) 'midpoint 
transition' could clearly be distinguished: an increase in task conflict during the middle time block was followed by a decline in task conflict during the last time block. Relationship conflict was low, but rose significantly during the last time block. Low performing groups did not experience such a midpoint transition, but instead experienced a large increase in task and relationship conflict toward the end.

The results from this study are intriguing, as the authors clearly demonstrate that conflict must be examined as a dynamic process, rather than as a static event (Jehn \& Mannix, 2001). One question that emerges from their results, however, is: To what extent are the results on the evolution of conflict context specific? Participants in the study worked in task groups: groups that were put together to complete specific tasks in a limited, pre-defined period of time. When translating these results to teams that perform complex tasks over longer periods of time and without a specific deadline associated with the completion of the task, a number of characteristics of the conflict pattern as found by Jehn and Mannix (2001) might disappear. Dynamic equilibrium theory (Gersick, 1988, 1989), on which the authors base their explanations about the evolution of conflict, is more difficult to apply to teams that work without specific deadlines. The midpoint transition which is triggered by the awareness of the time remaining before a deadline(Gersick, 1988, 1989), might be less obvious in these situations. Furthermore, the expected increases in task and relationship conflict towards the specific deadline might not occur.

Moreover, task and relationship conflict are often not independent (De Dreu \& Weingart, 2003). De Dreu and Weingart (2003), in their meta-analysis of 24 effect sizes, report a mean correlation of .54 between the two types of conflict. It has been suggested that the mechanism underlying the correlation between the two constructs is one of misattribution (Amason, 1996; Jehn \& Mannix, 2001; Simons \& Peterson, 2000). This implies that when task conflict in a group is perceived as a personal attack rather than as a discussion on task 
related issues, task conflict can trigger relationship conflict. On the other hand, relationship conflict can trigger task conflict, when incompatibilities in personal issues are mistaken for differences relating to the task at hand. This interdependency of task and relationship conflict has implications for the evolution of conflict.

When these relationships persist over time, a steady increase in both task and relationship conflict may be the result (Jehn \& Mannix, 2001). This pattern could be described as a deviation-amplifying loop in which a deviation in one variable (an increase in task conflict) leads to a similar increase in another variable (increase in relationship conflict), which, in turn, continues to amplify (Lindsley, Brass, \& Thomas, 1995). The existence of an amplifying loop makes it difficult to determine cause and effect (Weick, 1979); task and relationship conflict both act as cause and as effect. Therefore, we propose to focus on the pattern of joint evolution of task and relationship conflict as the relevant unit of analysis, rather than the bivariate relationship.

\section{Dynamics of Trust}

It is well established that trust has a significant impact on individual and organizational performance (Dirks \& Ferrin, 2002; Costa et al., 2001; McAllister, 1995). Teams with high levels of trust, as compared to teams with low levels of trust, exchange ideas more openly, search more extensively for alternative courses of action and have greater motivation to implement conclusions (Zand, 1972). On the other hand, deficits of trust in teams are shown to be associated with high stress, low satisfaction and relationship commitment and low task performance (Costa et al., 2001).

The evolution of trust has been the source of theoretical work. Very few studies have empirically studied this evolution. An influential dynamic model that has been proposed is Jones and George's (1998), in which trust is proposed to evolve through three different states 
of trust - conditional, unconditional and distrust. Each state contributes to teamwork in a different way. When conditional trust is present, parties are willing to interact with each other as long as the behavioural expectations are met. They are, in other words, continually testing each other's trustworthiness. When unconditional trust exists, the trustworthiness of the other party is assured and confidence in the other's values exists. Since, to our knowledge, no empirical work exists on Jones \& George's (1998) model, it is difficult to assess whether the different types of trust - conditional and unconditional - also relate to different levels of trust. Will the perceived level of trustworthiness in the case of unconditional trust be higher than in conditional trust? This question becomes even more interesting in a temporal perspective. When viewed in a temporal perspective, Jones and George (1998) argue that the conditional trust that characterizes a team at the start can evolve in two different ways depending on the behavioural interactions and experiences among the parties. Conditional trust can evolve into unconditional trust when the experiences of team members remain positive higher, while conditional trust ends in distrust when expectations are not reciprocated. Trust, in other words, spirals downwards. A downward spiral has also been proposed -but not tested- by Zand (1972).

\section{Dynamic Interaction of Conflict and Trust}

Cross-sectional research has shown that trust moderates the relationship between task and relationship conflict and reduces the likelihood of misattribution of task conflict (Simons \& Peterson, 2000). If group members trust each other, disagreements with respect to the task are less likely to be misinterpreted as personal attacks. However, if group members distrust each other, disagreements with others on the tasks are easily interpreted in a negative personalized manner. Some evidence for this effect in a longitudinal context was found by (Peterson \& Behfar, 2003) who studied the dynamic relationship between conflict and 
performance in a setting where task and relationship conflict were evoked by initial performance feedback. They observed that a high level of trust helps to prevent the development of relationship conflict.

Following Jones \& George (1998), we assume that behavioural exchanges between team members over time determine the level of trust within the team. Teams start with a certain level of conditional trust which is necessary to start functioning as a team. During the very early stages of a team's life, by shaping the attitudes, moods and emotions toward the other party, a mutual perception of trustworthiness is created (Jones \& George, 1998). This perceived trustworthiness can then evolve in two different ways; either trust remains to exist or trust gradually disappears. When perceived trustworthiness among team members is high, it becomes unlikely that task conflict will be perceived as a personal attack rather than as a difference in opinion on the task at hand. This implies that the process of misattribution (Amason, 1996; Jehn \& Mannix, 2001; Simon \& Peterson, 2001) is less likely to occur and that thus the start of a deviation-amplifying loop is prevented (Lindsley \& Thomas, 1995). In a way, the high level of trust makes sure that the level of task and relationship conflict remains contained within certain margins (Peterson \& Behfar, 2003). As a result this pattern will evolve in a relatively stable manner over time.

A very different pattern will occur when trust fails to develop within the team and exchanges between team members lead to decreasing perceptions of trustworthiness. In this case, trust will not be able to prevent misattribution: a discussion on task-related issues will be more easily misperceived as a personal conflict resulting in negative emotions among team members. As time progresses, a deviation-amplifying loop may be triggered, in which task conflict leads to relationship conflict, which in turn increases task conflict, which increases relationship conflict etc. etc. In this case, increasing levels of relationship and task conflict over time will further deteriorate the perceptions that team members have of each others 
trustworthiness, leading to a further decline in trust. Although the actual development of conflict and trust over time may take different forms, we expect that the two types of developments described here will prevail. More specifically, we hypothesize that:

Hypothesis 1: Teams that develop a high level of trust early on will show moderate, stable levels of task and relationship conflict over time.

Hypothesis 2: Teams that develop a low level of trust early on will show increasing levels of task as well as relationship conflict over time.

The temporal configuration of task conflict, relationship conflict and trust as stated in these hypotheses will be referred to as patterns. We will designate the first pattern with a high level of trust and moderate levels of task and relationship conflict as a stable pattern, and the second pattern with a low level of trust and increasing levels of task and relationship conflict as an unstable, deteriorating pattern.

\section{Patterns of Conflict and Trust in Relation to Team Effectiveness}

In the literature, the relationship between conflict and team effectiveness has been viewed from various perspectives. Most often, an information-processing perspective is proposed, which suggests a curvilinear relationship between conflict and information processing. In this approach it is assumed that team effectiveness will benefit from moderate levels of conflict, but not from either high or low levels. If conflict levels are too low this leads to inactivity and neglect of information while as conflict is too high, the cognitive load increases and generating ideas and solutions becomes impossible. In both cases effectiveness is likely to suffer (De Dreu \& Beersma, 2005). 
In the conflict typology framework by Jehn $(1994,1995)$ task conflict is seen as beneficial to team effectiveness in non routine tasks, since it forces team members to actively engage in discussing task related issues and searching for new solutions with respect to the task at hand. This leads the team to be more effective and innovative. In routine tasks, however, task conflict is disruptive since it interferes with standard operating procedures rather than improve on them. Relationship conflict is viewed as dysfunctional in any case since dealing with relationship conflict takes away time and energy from dealing with the task at hand. It thus interferes with team effectiveness (Jehn \& Bendersky, 2003).

Since we specifically focus on teams with complex tasks, task conflict would thus be beneficial for effectiveness, provided that it is moderate and does not extend into relationship conflict. Relationship conflict would in all cases impair effectiveness, regardless of the type of task. With respect to trust and team effectiveness, research suggest that trust is positively associated with measures of team effectiveness (Costa et al, 2001; Peterson \& Behfar, 2003). Thus, we come to the following hypothesis.

Hypothesis 3: Teams that over time show a high level of trust and moderate level of task and relationship conflict (and thus operate in a stable pattern) are more effective than management teams that over time show a low level of trust and increasing levels of task and relationship conflict (and thus operate in an unstable, deteriorating pattern).

\section{METHODS}

\section{Sample and Procedures}

As our sample we have chosen management teams of student associations in The Netherlands. These teams are the executive board of the student association and have a full-time job and 
responsibility in managing the student association. The nature of the tasks the teams perform is complex and resembles those of a top management team: the tasks are not well defined, involve diverse and uncertain information and relate to many different stakeholders (members, the university and municipal and federal government). Furthermore, since the teams are positioned at the top of their organization, they also have a symbolic value to all stakeholders.

The reason for studying these teams is that they combine the advantage of being relatively easy accessible with the fact that they perform natural tasks over a longer period of time. All teams started working as a team around September 2004 and worked together for 12 months. Because the composition of the team remained stable within this period, we could study the total life-span of the teams.

Websites of all universities and student related institutions in The Netherlands were searched for references to student organizations. This resulted in a sample of about 90 associations. Criteria we used for inclusion of a team in the study were 'the team has to fulfil a fulltime task', 'the student association has to count at least 200 members' and 'the starting point of the team has to be in September 2004'. 55 teams were approached with a written request for participation to the study. 44 teams confirmed their participation, a response rate of $80 \%$. Due to several reasons, three management teams had to be removed from the sample: one team had to be excluded after the second measurement point, due to a lack of cooperation, another team split up after five measurement moments, thereby making it impossible to track behavior for the full research period. The third management team needed to be excluded from the sample because their responses turned out to be severely biased. Therefore, the final sample consists of 41 management teams. The sample comprised 271 team members, $57 \%$ of whom were male. The average team-size was 6.6 persons and the mean age of the respondents was 23 years. 
Data collection took place during six intervals within a period of ten months. T1 was between October 4 and October 16 2004, T2 between November 22 and December 3 2004, T3 between January 10 and January 21 2005, T4 between February 24 and March 11 2005, T5 between April 25 and May 6 2005, and T6 between June 20 and July 1 2005. Within these periods, five researchers made personal visits to the teams and asked all team members to complete a questionnaire. Filling out the questionnaires took about 20 minutes, after which these were collected by the researcher immediately. Occasionally, when a team member was absent, a response envelope was left behind that had to be returned as soon as possible. All team members of every team completed the questionnaire at each different time period.

\section{Measures}

At time 1, team composition variables were investigated (that were not further analyzed for this study). Relationship conflict, task conflict and trust were investigated at time 2, time 3 , time 4, time 5, and time 6. For team effectiveness, we obtained two different measures: a selfperception measure of the team members at time 6 , and an external rating by the main stakeholders of these management teams, namely the members of the student associations. The members were able to observe the functioning of the board over the past year; they evaluate the functioning of the board in their annual meeting and have the right to appoint/dismiss board members. This rating took place during a period of three weeks, just before time 6 .

Relationship conflict was measured by Jehn's (1995) conflict scale, which comprises 4 items for this variable. Items were translated into Dutch and adapted to the longitudinal research design of the study. A typical item is 'Indicate for the past six weeks how often 
people got angry while working in your group.' Cronbach's $\alpha$ were .82 at time 2, .79 at time $3, .83$ at time $4, .85$ at time 5 , and .85 at time $6 .^{1}$

Task conflict was measured by Jehn's (1995) conflict scale, which comprises 3 items for task conflict. Items were translated into Dutch and adapted to the longitudinal research design. A typical item is 'Indicate for the past six weeks how much conflict of ideas was present in your group.' Cronbach's $\alpha$ were .56 at time $2, .58$ at time $3, .65$ at time $4, .68$ at time 5, and .71 at time 6 . The increase in alpha suggests that task conflict becomes a more established phenomenon over time.

Trust was measured by presenting the respondents with a definition that reflects trustworthiness (McAllister, 1995). The definition was: 'Trust is the extent to which you feel you can count on another person in situations in which this is important to you'. Respondents were then asked to estimate for each of their fellow team members to what extent they could trust them. A 7-point Likert scale, anchored by very little and very much, was used. This way, each team member received a trustworthiness score. The scores per team member were averaged to reflect the average trustworthiness that other members of the team attributed to that particular team member.

Team effectiveness (self perception) was been measured by 7 items that were based on the measure of team effectiveness by (Flood et al., 2000) Since this scale had showed reliable psychometric properties in previous research (Flood et al., 2000), it was considered to be an adequate scale to measure self-perceived team effectiveness. Items were translated into Dutch and adapted to the longitudinal context of the research and the specific sample. For example, the item "our company goals are clear in the minds of every member of the TMG" was transformed into "the goals of this association were clear for every member of the management team”. Cronbach's alpha for this scale was 0.81 .

\footnotetext{
${ }^{1}$ All reliability analysis (Cronbach's alpha) have been performed on individual level data
} 
Team effectiveness (external measure). To avoid common-source biases due to the fact that both dependent and independent measures are self-perceptual, we performed an external measure to assess the effectiveness of the management teams. The main stakeholders of the management teams, namely the members of their student associations were asked to indicate how effective they considered their management team to be. Questionnaire development for the external effectiveness measure was guided by answers provided by the management teams themselves. At time 2 we asked them an open question: 'Describe how one can see how effective the management team you are a part of is'. The attributes identified were used as questionnaire items. A pilot study of this questionnaire among 10 people involved in student life (but not part of the target organization) had lead to some revisions of the questions. A sample item for this dimension of team effectiveness is "the management team does contribute to the design of new activities" and "the board reached their goals". In Appendix A, the complete version of the questionnaire for the members of the students association is presented.

Although all management teams were approached for participation in this external measure of team effectiveness, the final sample consisted of the members of 28 student associations only. In total, the sample comprised 2218 members. The number of members of associations varied between 20 and 168 with a mean of 79 members. The mean response rate per association was $19 \%$ of the members, and response rates varied between $6 \%$ and $35 \%$. Cronbach's alpha for this scale was 0.95 . An exploratory factor-analysis showed that one factor accounted for $46 \%$ of the variance. We used an un-weighted mean of the item scores as our measure of effectiveness. 


\section{Aggregation}

Since the unit of analysis in this study was the team, individual data had to be aggregated to a team level for further analysis. Several psychometric formulas exist to justify this aggregation, the most common being: one-way analysis of variance, inter-rater reliability $R_{\mathrm{wg}}$ (James, Demaree, \& Wolf, 1984).

Conflict. Results of one-way analyses of variance indicated for task and relationship conflict on all measurement moments significant between-group variances with F-values between 2.05 and 4.85 and $p<0.00$. Table 1 indicates that for task and relationship conflict on the different moments, $R_{\mathrm{wg}}$ values ranged between 0.85 and 0.88 . An $R_{w g}$ above 0.70 indicates an acceptable interrater reliability and consensus, which means that aggregation to team level has been justified (Harvey \& Hollander, 2004).

Insert Table 1 about here

Team effectiveness (self-perception). For this variable, results of a one-way analysis of variance $(F=4.04, p<0.01)$ indicated justification of aggregation. A mean $\mathrm{R}_{\mathrm{wg}}$ value of 0.97 $(\mathrm{sd}=0.01$ with minimum $=0.93$ and maximum $=0.99)$ provided further evidence for this conclusion.

Team effectiveness (external). Results of a one-way analysis of variance resulted in $\mathrm{F}$ $=17.58$ and $\mathrm{p}<.00$, thereby justifying aggregation. A mean $\mathrm{R}_{\mathrm{wg}}$ value of $0.8997(\mathrm{sd}=0.04$ with minimum $=0.78$ and maximum $=0.95)$

Trust. The data on trust are individual-on-individual data. To calculate the trustworthiness score for each team member, the individual assessments of other team members were averaged for that particular person. Since the assessments of other individuals members are not considered to be parallel measures of the same construct, no specific aggregation method, other than averaging at the team level, is used. 


\section{Data Analysis}

To examine conflict patterns over time - as suggested in hypotheses 1 and 2 -, a cluster analysis was performed to classify the teams according to their scores on trust, task and relationship conflict on the five measurement points. Cluster analysis is a technique that is frequently employed to search for groups in data, using measures of similarity (or dissimilarity) to determine membership either within a given group or across different groups. Clustering on trust, task and relationship conflict was justified given that these are our theoretical constructs of interest (Ketchen \& Shook, 1996). Using Ward's hierarchical method with squared Euclidian distances (Hair, Anderson, \& Black, 1998) a two cluster solution was identified. To determine that and how the clusters differed from one another, analysis of variance (ANOVA) was used. The results for all relevant variables at the different moments in time suggest a robust cluster classification. Specific F-values and levels of significance are presented below.

To assess whether the pattern over time was either stable or unstable, we conducted a repeated-measures multivariate analysis of variance (MANOVA) on relationship conflict, task conflict, trust and time period (Jehn \& Mannix, 2001). To test the relationship of the different patterns to team effectiveness - as stated in hypothesis 3 - again ANOVA was used.

\section{RESULTS}

Hypotheses 1 and 2 proposed relationships over time between trust, task and relationship conflict. The cluster analysis revealed that the evolution of these concepts over time follows two distinct patterns. To examine these temporal patterns in more detail, the two clusters are analyzed by using ANOVA on all the variables over time. The results of the ANOVA are presented in Table 2 . 
Insert Table 2 about here

Results indicate significant differences between the clusters on all variables except one. There is no significant difference in level of task conflict between the clusters at $t=2$. Overall, cluster 1 is characterized by higher levels of relationship conflict, higher levels of task conflict and a lower level of trust than cluster 2. This implies that higher levels of relationship and task conflict and a lower level of trust on the one hand as well as lower levels of relationship and task conflict and a higher level of trust on the other hand, go together.

The ANOVA also reveals a strengthening of the distinctiveness of the clusters over time. Where the difference between the clusters is barely significant (for relationship conflict and trust) or even insignificant (for task conflict) at $\mathrm{t}=2$, from $\mathrm{t}=3$ onward the difference between the two clusters on all variables is highly significant.

To gain more insight in the dynamic nature of the cluster patterns, the means of relationship conflict, task conflict and trust are plotted over time. Figures 1, 2 and 3 display the results.

\section{Insert Figures 1, 2 and 3 about here}

Visual inspection of the development over time yields the impression of one stable cluster and one less stable cluster. The repeated measures MANOVA on relationship conflict, task conflict, trust and time period confirms the results of the visual inspection. Results indicate that for all three variables the interaction of time period and cluster membership was significant implying that the development of these variables over time indeed proceeds in a distinctly different manner. The associated values were for relationship conflict $\mathrm{F}=2.42$, $p=.066$, for task conflict $\mathrm{F}=3.10, p=.027$ and for trust $\mathrm{F}=5.08, p=.002$. 
In addition (in)stability of the variables within each cluster over time was tested by a within cluster MANOVA. Within cluster 1 a significant time effect exists with respect to relationship conflict $(\mathrm{F}=5.12, p=.006)$, task conflict $(\mathrm{F}=4.16, p=.016)$ and trust $(5.28, p=.006)$. This implies that the pattern is instable over time. Within cluster 2 the time effect for relationship conflict $(\mathrm{F}=2.79, p=.062)$, task conflict $(\mathrm{F}=.825, p=.528)$ and trust $(\mathrm{F}=2.51, p=.083)$ is not significant. This suggest a stable pattern for relationship conflict, task conflict and trust.

These results suggest that hypothesis 1 is supported. The teams in cluster 2 indeed show a high, stable level of trust early on and a moderate, stable level of relationship and task conflict. Hypothesis 2 is also supported. Cluster 1 shows a pattern of an instable, low level of trust early on together with high, unstable levels of relationship and task conflict.

Hypothesis 3 suggested that teams exhibiting patterns of high trust and moderate levels of task and relationship conflict over time are more effective than teams showing patterns of low trust and increasing levels of task and relationship conflict. Since cluster 1 contains teams with increasing levels of relationship and task conflict and lower levels of trust and cluster 2 comprises teams with higher trust and moderate, stable levels of relationship and task conflict, ANOVA on the clusters is performed. Results support differences between the clusters on team effectiveness $\left(\mathrm{F}_{\text {self-perceived }}=11.81, p=.001, \mathrm{~F}\right.$ stakeholders $\left.=4.86, p=0.037\right)$. Furthermore, examination of the means shows that on the self-perceived measure, cluster 1 reports a significantly lower mean $(3.73, \mathrm{SD}=.33)$ than cluster $2(4.03, \mathrm{SD}=.22)$. On the effectiveness measure as perceived by stakeholders a similar patterns exists with cluster 1 performing worse (3.47, $\mathrm{SD}=.33)$ than cluster $2(3.7, \mathrm{SD}=.32)$. Hypothesis 3 is thus supported. 


\section{DISCUSSION AND CONCLUSION}

"Although the importance of dynamic conditions experienced over time are accepted by all, the empirical work is only beginning to consider the implications of time in research designs" (Ilgen et al., 2005, p. 536). In the present study, we incorporated time in our research design to identify patterns of conflict and trust over time in relation to team effectiveness. All three hypotheses on these patterns were supported by our data.

Our data reveal two distinctly different types of patterns of conflict and trust over time. One is a stable pattern where a relatively high level of trust occurs together with moderate levels of task and relationship conflict. The other is an unstable pattern where the level of trust is low and decreasing over time, while the level of relationship as well as task conflict is increasing. As predicted in hypothesis 3, the stable pattern was associated with higher team effectiveness than the unstable pattern. These findings relate to some of the core ideas of Complex Action System Theory (CAST) (McGrath \& Tschan, 2004). CAST suggests that with respect to system-level variables such as conflict or trust, it is important to trace the trajectory or pattern of evolution over time. In that view, conflict and trust do not belong to a certain stage or phase - as for example Wheelan (1994) would suggest - but are meaningful processes by themselves that over time shape the interdependencies among members of the team and the context they operate in.

Further analysis of the nature of the unstable pattern also yielded a quite unexpected but interesting result. Visual inspection of Figures 1 and 2 shows that towards the end of the life time of the teams, a sharp drop in relationship as well as task conflict occurred. Although not halfway through the life time of the group, the drop ressembles the midpoint transition as identified by Gersick (1988). In her research among task groups it appeared that new groups immediately formed a framework of givens about its situation and how it would behave. At the halfway point, groups explicitely dropped old approaches and searched for new ones by 
creating new perspectives and introducing new modes of working. The teams in our study differ from Gersick's sample in the sense that they are not task groups with a specific task to be completed before a specific deadline. Our student boards are in charge of the student assocation for the period of one year. We believe that with the end of the appointment duration in sight, the teams start to notice that the escalating conflict will not produce an effective transition to the new student board that will take over the following year. They thus start to put what is happening in their board in perspective and allow feedback from outside to alter their modes of working: a transition very similar to Gersick's (1988) midpoint. The reason for not detecting the same phenomenon in the stable teams could be due to a continuous awareness of these teams of their own functioning and therefore no need to alter their way of working before the handing over to a new board would take place. Making this part of the explanation would imply a significant difference in levels of reflexivity among the stable and unstable teams. This leads to the most prominent question for future research: what conditions distinguish teams with different temporal patterns from one another?

The arguments above suggest that looking at differences in levels of reflexivity might be an interesting angle for future research. West (forthcoming) argues that teams operating in uncertain challenging environments will be more effective to the extent that they reflect upon their own functioning and act based on the results of this reflection. The proposition based on our results would then be that stable teams are better able to do this than unstable teams.

Complexity theory would argue that differences in initial conditions might be an important variable to consider (McGrath \& Tschan, 2004). This notion has been supported by other small group research on early successes and failures in a group's life (e.g. Cohen \& Denison, 1990). Initial conditions can include analyzing demographic and personality characteristics of team members, but also examining initial states of trust and conflict. A key question in this respect is whether trust can develop without constraints and, when a high 
level has been achieved, finds itself in a stable pattern or whether trust at the very start of the team's life determines the development over time.

Next to the level of trust, the type of trust could be an important variable to examine. Jones \& George (1998) distinguish between unconditional trust - which is based on shared values - versus conditional trust. The concept of unconditional trust bears resemblance to what Jehn (1994) calls trust created by similar pre-established work values. The existence of unconditional trust might help prevent task conflict from being misperceived as relationship conflict or at least prevent it long enough for the different team members to develop their own distinct way of working. Different types of trust at the start of the team might thus lead to different patterns.

The practical implications of the findings can also be found in this area. The dominant question here is: how can one foster task conflict in teams -after all Jehn $(1994,1995)$ indicated that this was beneficial for performance in non-routine decisions (as our teams face)- without the risk of misattribution and subsequently creating a deviation-amplifying loop? Our results suggest that trust plays a very important role. This implies that selection based on shared (work) values and explicit attention to or training in team processes might be important human resource issues to consider.

This study has at least two important limitations to consider. First, although our data indeed seem to suggest that the level of trust early on in the teams life plays an important role, we did not examine the level of trust and conflict at $t=1$. At $t=1$ we collected team composition variables (not analyzed in this study). Since we wanted to ensure cooperation of all team members during all six measurement moments over the 12 -months period, we did not want to overburden the team members with a too lengthy questionnaire at $\mathrm{t}=1$.

The second limitation is that although our study was longitudinal, the methods used do not permit inferences about causality. We did not test whether task conflict at $t=2$ lead to 
relationship conflict at $\mathrm{t}=3$, which lead to increases in task conflict at $\mathrm{t}=4$ etc. etc. We thus assume the existence of a deviation-amplifying loop in the unstable pattern but did not directly test this.

However, given that this is one of the first studies empirically examining patterns of conflict and trust over time in teams performing natural tasks, we hope that the value and external validity of this study off sets some of these limitations and nonetheless demonstrates the opportunities in studying patterns of interaction over time. 


\section{REFERENCES}

Amason, A. C. (1996). Distinguishing the effects of functional and dysfunctional conflict on strategic decision making: Resolving a paradox for top management teams. Academy of Management Journal, 39, 123 - 148.

Arrow, H., McGrath, J. E., \& Berdahl, J. L. (2000). Small groups as complex systems: Formation, coordination, development, and adaptation. Thousand Oaks, California: Sage Publications, Inc.

Bateson, P. (1988). The biological evolution of cooperation and trust. In D. Gambetta (Ed.), Trust: Making and breaking cooperative relations, 14-30, Basil Blackwell, New York.

Cohen, S.G. \& Denison, D.R. (1990). Flight attendant teams. In J.R. Hackman (Ed.), Groups that work (and those that don't), 382-397. Jossey-Bass, San Francisco.

Costa, A. C., Roe, R. A., \& Taillieu, T. (2001). Trust within teams: The relation with performance effectiveness. European Journal of Work \& Organizational Psychology, 10(3), 225- 244.

De Dreu, C.K.W. \& Beersma, B. (2005). Conflict in organizations: Beyond effectiveness and performance. European Journal of Work and Organizational Psychology, 14(2), 105117.

De Dreu, C. K. W., \& Weingart, L. R. (2003). Task versus relationship conflict, team performance, and team member satisfaction: A Meta-Analysis., Journal of Applied Psychology, 88, 741-749.

Dirks, K.T. \& Ferrin, D.L. (2002). Trust in leadership: Meta-analytic findings and implications for research and practice, Journal of Applied Psychology, 87(4), 611-628.

Flood, P. C., Hannan, E., Smith, K. G., Turner, T., West, M. A., \& Dawson, J. (2000). Chief executive leadership style, consensus decision making, and top management team effectiveness. European Journal of Work \& Organizational Psychology, 9(3), 401420.

Gersick, C. J. G. (1988). Time and transition in work groups: Toward a new model of group development. Academy of Management Journal, 31(1), 9- 41.

Gersick, C. J. G. (1989). Marking time: Predictable transitions in task groups. Academy of Management Journal, 32(2), 274-309.

Gevers, J. M.P. (2004). It's about time we align: Meeting deadlines in project teams, Unpublished doctoral dissertation. Eindhoven: Technische Universiteit Eindhoven.

Hair, J.F., Anderson, R.E., Tatham, R.L. \& Black, W.C.(1998) Multivariate data analysis. Upper Saddle River, NJ: Prentice-Hall International, Inc.

Harvey,R.J. \& Hollander, E. (2004). Benchmarking $\mathrm{r}_{\mathrm{wg}}$ interrater agreement indices: let's drop the .70 rule of thumb. Paper presented at the Annual Conference of the Society for Industrial and Organizational Psychology, Chicago.

Ilgen, D. R., Hollenbeck, J. R., Johnson, M., \& Jundt, D. (2005). Teams in organizations: From input-process-output models to IMOI models. Annual Review of Psychology, 56, 517-543.

James, L.R., Demaree, R.G., \& Wolf, G. (1984). Estimating Within-group Interrater Reliability With and Without Response Bias. Journal of Applied Psychology. 69 (1), 85-98.

Jehn, K. A. (1995). A multimethod examination of the benefits and detriments of intragroup conflict. Administrative Science Quarterly, 40, 256-282.

Jehn, K.A., (1994). Enhancing effectiveness: An investigation of advantages and disadvantages of value-based intragroup conflict, International Journal of Conflict Management, 5, 223-238. 
Jehn, K. A., \& Bendersky, C. (2003). Intragroup conflict in organizations: A contingency perspective on the conflict-outcome relationship. Research in Organizational Behavior, 25, 187-243.

Jehn, K. A., \& Mannix, E. A. (2001). The dynamic nature of conflict: A longitudinal study of intragroup conflict and group performance. Academy of Management Journal, 44, 238 $-251$.

Jehn, K. A., \& Shah, P. P. (1997). Interpersonal relationships and task performance: An examination of mediating processes in friendship and acquaintance groups. Journal of Personality \& Social Psychology, 72(4), 775-790.

Jones, G. R., \& George, J. M. (1998). The experience and evolution of trust: Implications for cooperation and teamwork. Academy of Management Review, 23(3), 531-546.

Ketchen Jr., D. J., \& Shook. C.L. (1996), The application of cluster analysis in strategic management research: an analysis and critique. Strategic Management Journal, 17(6), 441-458.

Lindsley, D. H., Brass, D. J., \& Thomas, J. B. (1995). Efficacy-performing spirals: A multilevel perspective. Academy of Management Review, 20(3), 645-678.

Mayer, R.C., Davis, J.H. \& Schoorman, F.D. (1995). An integrative model of organizational trust. Academy of Management Review, 20, 709-734.

McAllister, D. J. (1995). Affect- and cognition-based trust as foundations for interpersonal cooperation in organizations. Academy of Management Journal, 38(1), 24-59.

McGrath, J.E., Tschan, F. (2004). Temporal Matters in Social Psychology: examining the role of time in the lives of groups and individuals, APA, Washington DC.

McGrath, J. E., Arrow, H., \& Berdahl, J. L. (2000). The study of groups: Past, present, and future. Personality and Social Psychology Review, 4, 95-105.

Peterson, R. S., \& Behfar, K. J. (2003). The dynamic relationship between performance feedback, trust, and conflict in groups: A longitudinal study. Organizational Behavior \& Human Decision Processes, 92, 102-112.

Poole, M.S. \& Roth, J. (1989), Decision development in small groups. Human Communication Research, 15, 323-589.

Simons, T. L., \& Peterson, R.S. (2000). Task conflict and relationship conflict in top management teams: The pivotal role of intragroup trust. Journal of Applied Psychology, 85(1), 102-111.

Tuckman, B.W. (1965). Developmental sequences in small groups. Psychological Bulletin, 65, 384-399.

Waller, M.J. (1999), The timing of adaptive group responses tot nonroutine events. Academy of Management Journal, 42.2, 127-137.

Weick, K.E. (1979). Causal loops and control. The social psychology of organizing, 72-88. Addison-Wesley, New York.

West, M.A. (forthcoming). Reflexivity, revolution and Innovation in work teams. In M. Beyerlein (Ed.), Advances in Interdisciplinary Studies of Work Teams: product development teams, JAI Press, California.

Wheelan, S.A. (1994), Group processes: a developmental perspective, Allyn \& Bacon, Sydney.

Williams, M. (2001). In whom we trust group membership as an affective context for trust development. Academy of Management Review, 26.3, 377-396.

Zand, D. E. (1972). Trust and managerial problem solving. Administrative Science Quarterly, 17(2), 229-239.

Zucker, L.G. (1987). Institutional theories of organization. Annual Review of Sociology, 13, 443-464. 


\section{Appendix A}

\section{Items measuring team effectiveness (external perceived effectiveness measure)}

1. During the past year, I have been satisfied with the state of affairs within the association.

2. During the past year, the board has contributed to a good atmosphere within the association.

3. The board performed well with respect to its daily activities.

4. During the past year, I have been satisfied with the accessibility of the board.

5. The board was open to ideas of the members.

6. The board made clear what decisions were taken.

7. During the past year, I have been satisfied with the communication between the board and the members.

8. The board contributed to the development of new activities.

9. The board implemented improvements.

10. During the past year, I have been satisfied with the commitment of the board towards the members.

11. During the past year, I have been satisfied with the functioning of the board of my student association.

12. Conflicts within the association were handled well by the board.

13. During general meetings with the members, the board performed according to my expectations.

14. The board lived up to their promises.

15. The board implemented innovations.

16. The board did not incorporate the long terms goals of the association in its policy. (reverse scored)

17. The board informed the members about the current state of affairs.

18. The board handled unforeseen circumstances adequately.

19. The board performed its task seriously and professionally.

20. External conflicts (so: with parties outside the association) were handled well by the board.

21. The board appeared enthusiastic.

22. The board realized its goals. 


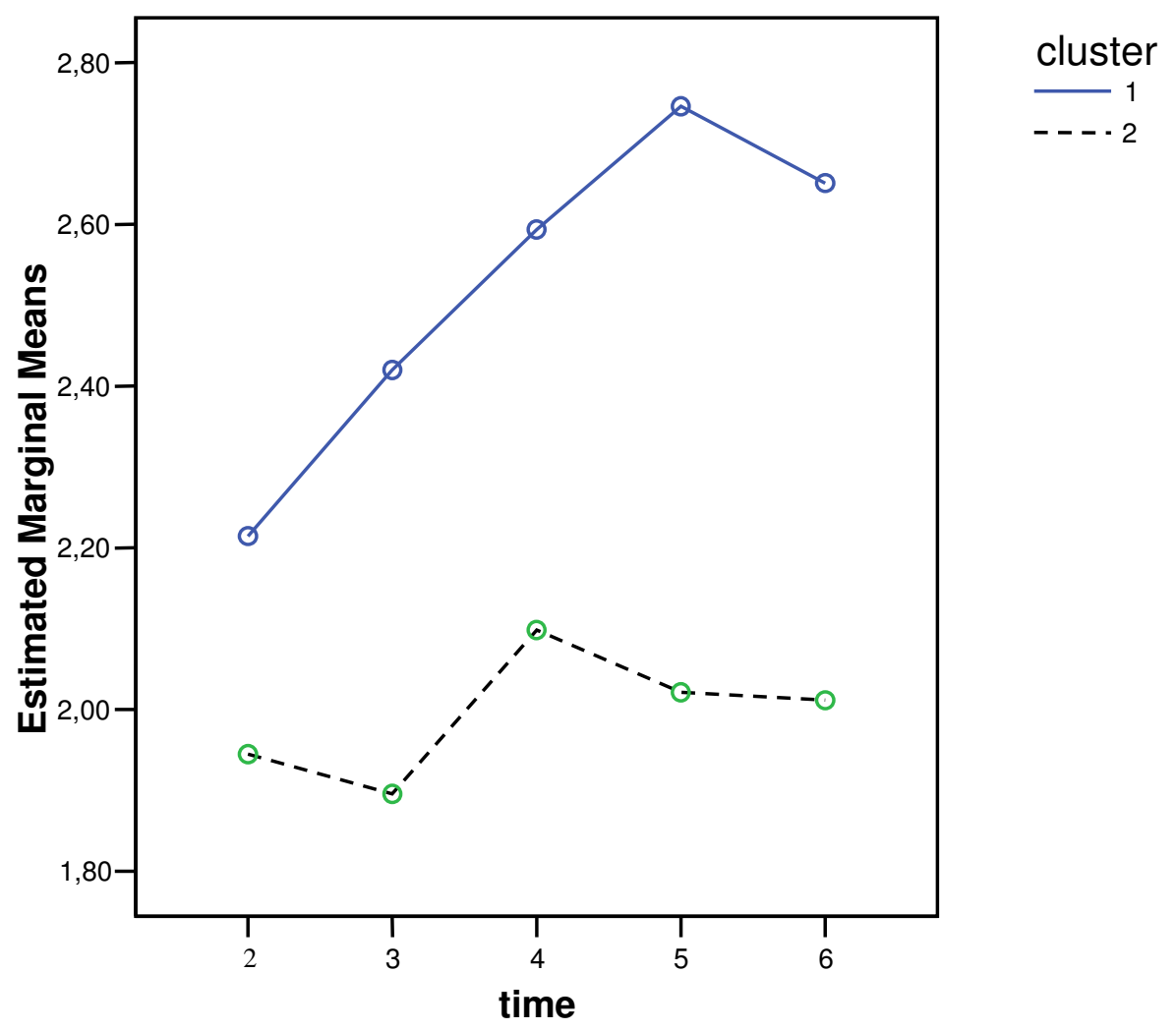

Figure 1: The evolution of relationship conflict over time in the two clusters 


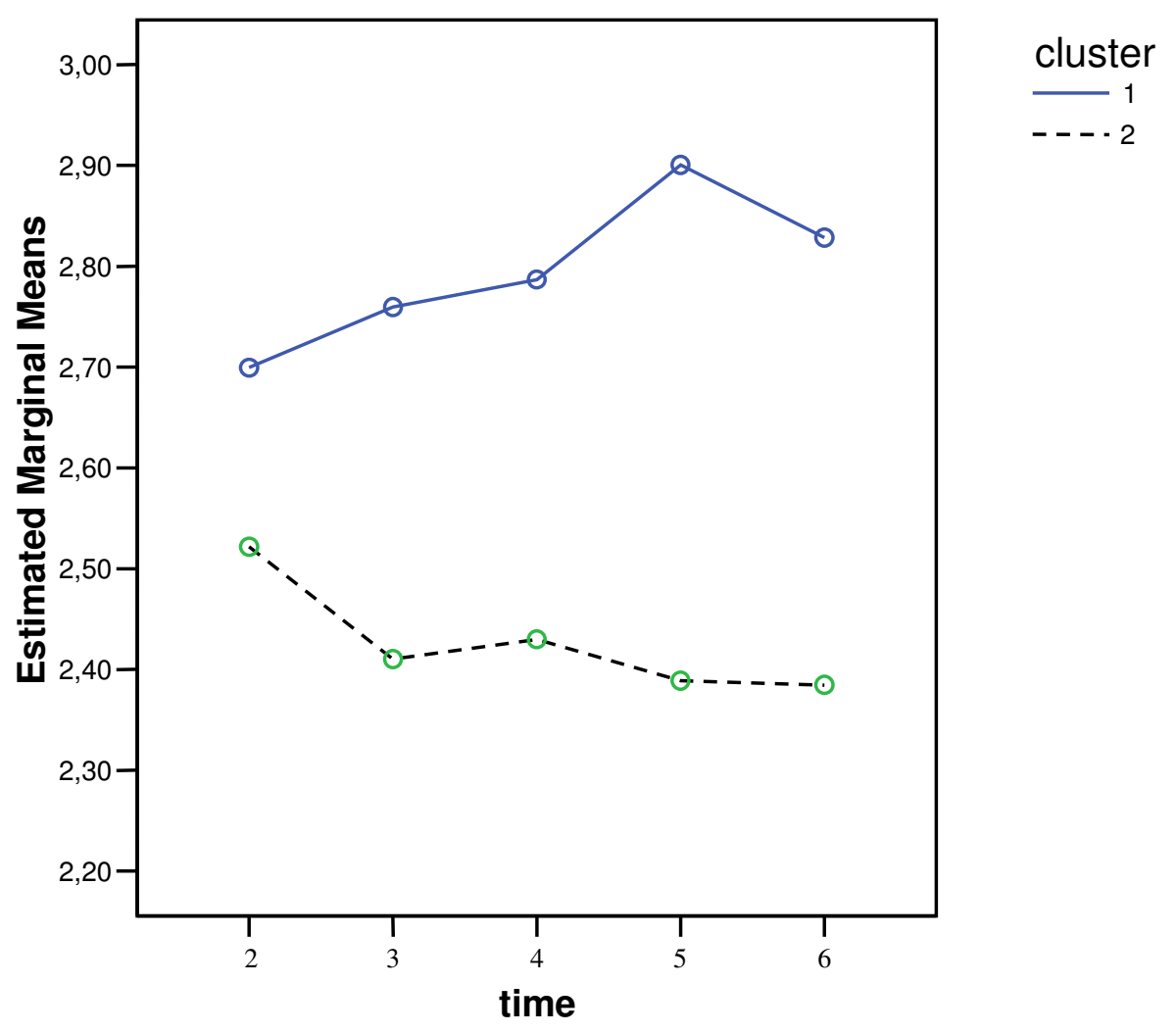

Figure 2: The evolution of task conflict over time in the two clusters 


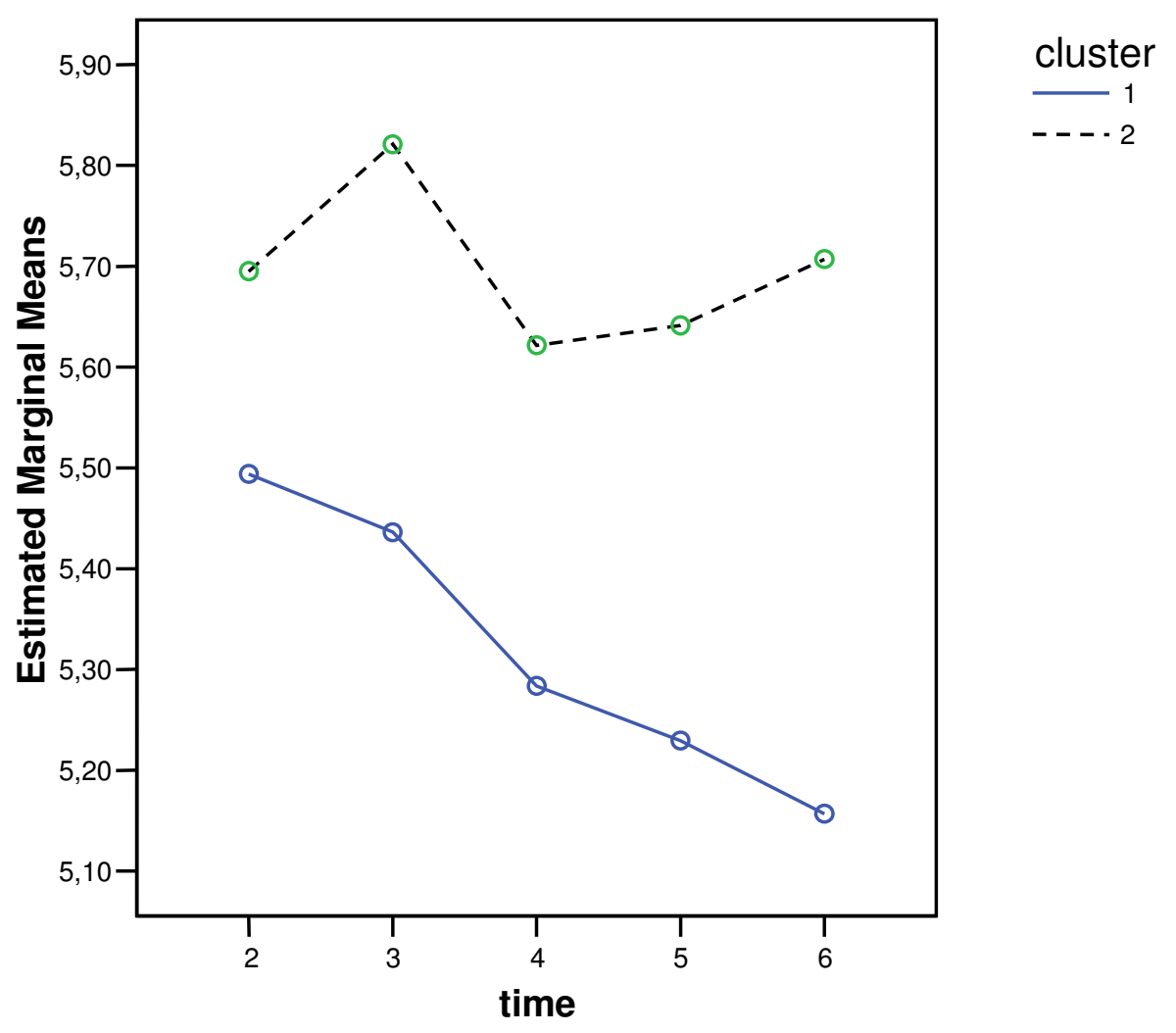

Figure 3: The evolution of trust over time in the two clusters 


\begin{tabular}{|l|c|c|c|c|}
\hline & Task conflict & $\begin{array}{c}\text { Relationship } \\
\text { conflict }\end{array}$ & $\begin{array}{c}\text { Effectiveness } \\
\text { (self-perception) }\end{array}$ & $\begin{array}{c}\text { Effectiveness } \\
\text { (stakeholders) }\end{array}$ \\
\hline T2 & .90 & .86 & n.a. & n.a. \\
\hline T3 & .85 & .88 & n.a. & n.a. \\
\hline T4 & .90 & .87 & n.a. & n.a. \\
\hline T5 & .89 & .87 & n.a. & n.a. \\
\hline T6 & .89 & .87 & 0.97 & 0.8997 \\
\hline
\end{tabular}

Table 1: Mean $\mathrm{R}_{\mathrm{wg}}$ values for relationship conflict, task conflict, and effectiveness 


\begin{tabular}{|c|c|c|c|c|c|c|c|c|}
\hline 离 & III & & $\begin{array}{l}0 \\
i n \\
i n\end{array}$ & 吕 & $\begin{array}{l}R \\
\text { in }\end{array}$ & $\widehat{\overbrace ్ త]}$ & $\mid \begin{array}{l}\text { సे } \\
\stackrel{\mathrm{N}}{ }\end{array}$ & $\underset{8}{8}$ \\
\hline$\stackrel{\overrightarrow{\hat{w}}}{\vec{E}}$ & III & & $\begin{array}{l}\hat{n} \\
\text { in }\end{array}$ & ָे & $\begin{array}{l}\text { d } \\
\dot{n} \\
\text { in }\end{array}$ & f & $\stackrel{0}{\stackrel{0}{0}}$ & $\widehat{\hat{\delta}}$ \\
\hline 总 & II & & $\begin{array}{l}\infty \\
\text { in } \\
i n\end{array}$ & & $\begin{array}{l}\text { W. } \\
\dot{b} \\
\text { in }\end{array}$ & త్రి & $\begin{array}{l}0 \\
\infty \\
\sigma \\
\sigma\end{array}$ & 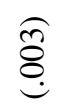 \\
\hline $\overrightarrow{\mid \vec{E}}$ & II & & $\begin{array}{l}f \\
\dot{y} \\
\text { in }\end{array}$ & 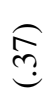 & $\mid \begin{array}{l}0 \\
\infty \\
i n \\
\text { in }\end{array}$ & $\stackrel{\overbrace{}}{?}$ & 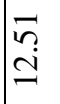 & $\widehat{\widehat{\sigma}}$ \\
\hline$\stackrel{\vec{E}}{\stackrel{E}{E}}$ & II & & $\begin{array}{l}q \\
\dot{q} \\
\text { in }\end{array}$ & ֻृ & $\stackrel{R}{i}$ & 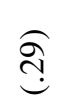 & $\begin{array}{c}\hat{\infty} \\
\infty \\
\end{array}$ & 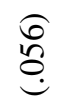 \\
\hline 童 & 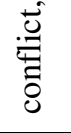 & II & $\begin{array}{l}\infty \\
\infty \\
i\end{array}$ & 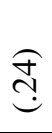 & 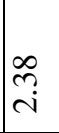 & 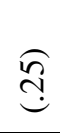 & $\begin{array}{l}\hat{\infty} \\
\infty \\
\tilde{m}\end{array}$ & $\stackrel{8}{8}$ \\
\hline 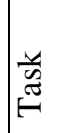 & 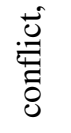 & III & @) & હે & ले & $\stackrel{\text { d }}{\text { d }}$ & $\begin{array}{l}f \\
\stackrel{f}{2} \\
\ddot{n}\end{array}$ & $\underset{\S}{8}$ \\
\hline 童 & 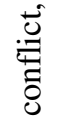 & II & $\stackrel{\substack{i \\
i}}{i}$ & 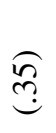 & $\stackrel{m}{\stackrel{m}{i}}$ & ఠ్ & $\stackrel{\infty}{\stackrel{\infty}{c}}$ & $\widehat{\overrightarrow{8}}$ \\
\hline 㕗 & 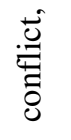 & II & $\stackrel{\bullet}{\stackrel{0}{i}}$ & $\underset{\overbrace{}}{\widehat{N}}$ & $\vec{F}$ & $\widehat{\stackrel{\overbrace ్}{\mathrm{j}}}$ & $\begin{array}{l}\vec{b} \\
\ddot{b} \\
a\end{array}$ & $\stackrel{8}{8}$ \\
\hline 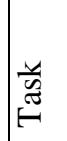 & 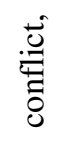 & $\mathbb{I}$ & $\stackrel{R}{i}$ & હ્ণ & ก̂n & $\stackrel{\infty}{\overbrace{}^{\infty}}$ & $\underset{\text { ì. }}{\hat{\sigma}}$ & $\underbrace{0}_{\substack{\infty \\
\infty}}$ \\
\hline 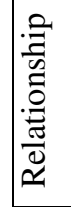 & 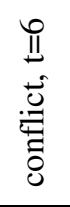 & & 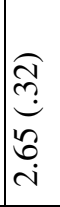 & & 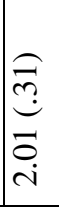 & & 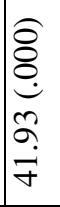 & \\
\hline 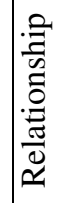 & 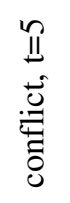 & & 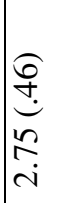 & & 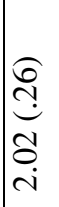 & & 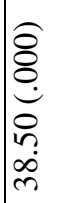 & \\
\hline 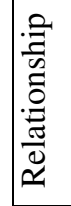 & 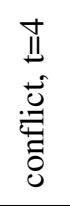 & & 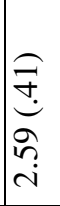 & & 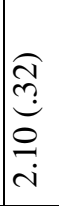 & & 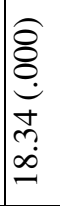 & \\
\hline 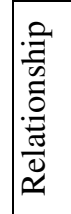 & 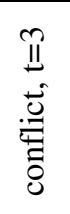 & & 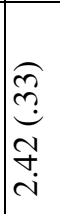 & & 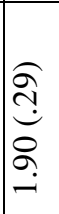 & & 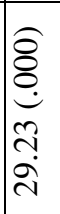 & \\
\hline 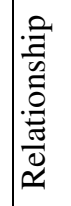 & 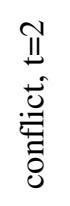 & & 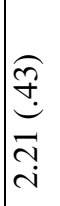 & & $\mid \begin{array}{l}\widetilde{\Omega} \\
\mathfrak{d} \\
\dot{\sigma} \\
\stackrel{\sigma}{-}\end{array}$ & & 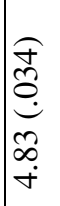 & \\
\hline 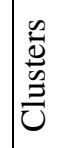 & & & - & & $N$ & & 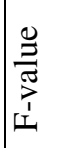 & \\
\hline
\end{tabular}

